\title{
Autophagy protein p62/SQSTM1 is involved in HAMLET-induced cell death by modulating apotosis in U87MG cells
}

\author{
Y-B Zhang ${ }^{1,2}$, J-L Gong ${ }^{1}$, T-Y Xing ${ }^{1}$, S-P Zheng ${ }^{1}$ and W Ding ${ }^{*, 3}$
}

\begin{abstract}
HAMLET is a complex of oleic acids and decalcified $\alpha$-lactalbumin that was discovered to selectively kill tumor cells both in vitro and in vivo. Autophagy is an important cellular process involved in drug-induced cell death of glioma cells. We treated U87MG human glioma cells with HAMLET and found that the cell viability was significantly decreased and accompanied with the activation of autophagy. Interestingly, we observed an increase in p62/SQSTM1, an important substrate of autophagosome enzymes, at the protein level upon HAMLET treatment for short periods. To better understand the functionality of autophagy and p62/SQSTM1 in HAMLET-induced cell death, we modulated the level of autophagy or p62/SQSTM1 with biochemical or genetic methods. The results showed that inhibition of autophagy aggravated HAMLET-induced cell death, whereas activation of authophagy attenuated this process. Meanwhile, we found that overexpression of wild-type p62/SQSTM1 was able to activate caspase-8, and then promote HAMLET-induced apoptosis, whereas knockdown of p62/SQSTM1 manifested the opposite effect. We further demonstrated that the function of p62/SQSTM1 following HAMLET treatment required its C-terminus UBA domain. Our results indicated that in addition to being a marker of autophagy activation in HAMLET-treated glioma cells, p62/SQSTM1 could also function as an important mediator for the activation of caspase-8-dependent cell death.
\end{abstract}

Cell Death and Disease (2013) 4, e550; doi:10.1038/cddis.2013.77; published online 21 March 2013

Subject Category: Cancer

HAMLET (Human $\alpha$-Lactalbumin Made Lethal to Tumor Cells) is a complex comprising decalcinated $\alpha$-lactalbumin and oleic acids. HAMLET was able to rapidly induce massive cell death of a wide spectrum of cancer or undifferentiated cells with selectivity both in vitro and in vivo. ${ }^{1-4}$ The cell responses to HAMLET were rather complex, involving multiple cellular organelles or components, such as mitochondria, ${ }^{5}$ histone, ${ }^{6}$ proteasomes, ${ }^{7}$ which were shown to interact with HAMLET inside the cells. Although apoptosis was observed in HAMLET-treated cells, the 'non-typical' activation of caspase-2, 3 and 9 strongly implied the existence of other cell death-related mechanisms. ${ }^{8}$ Recently, autophagy has been investigated in HAMLET-induced cell death, and was demonstrated to contribute to the lethal effect of HAMLET in certain cell types. ${ }^{9}$

Autophagy is a highly conserved system in eukaryotes for the bulk degradation of obsolete organelles or proteins to maintain cellular homeostasis or to struggle for the survival from starvation. Besides a set of core Atg proteins, ${ }^{10}$ p62 has recently become a interesting subject in autophagy studies, for its ability to crosstalk with both autophagy and apoptosis pathways in tumor cells. ${ }^{11}$ The protein of p62, also known as sequestosome 1 (SQSTM1), is one of the selective substrates for autophagy, as well as a scaffold in autophagosomes. It was identified to have a critical role in the formation of cytoplasmic proteinaceous inclusion. Being a multifunctional signal adapter protein, p62 conducts various functions through several structural domains, including PB1 (Phox/ Bem 1p), TB (TRAF6-binding), LIR (LC3-interacting region) and UBA (ubiquitin-associated) domains. ${ }^{11}$ The LIR domain is responsible for binding autophagy regulator Atg8/LC3, and directs different ubiquitinated proteins to the ubiquitin-proteasome system or autophagosomes. ${ }^{12,13}$ The UBA domain is required for oligomeric $p 62$ proteins to form aggregates, thus to serve as signal-organizing centers to recruit polyubiquitinconjugated proteins, especially when cells were exposed to oxidants $^{14}$ or proteasome inhibitors. ${ }^{15}$ Among the known ubiquitinated proteins of important functions, caspase-8 was recently found to interact with $\mathrm{p} 62$ and initiate a nondeath receptor-mediated pathway of apoptotic cell death. ${ }^{16}$ Therefore, to explore whether p62 is functionally involved in HAMLET-induced cell death can be both interesting and important in understanding the role of autophagy activation in response to HAMLET treatment.

\footnotetext{
${ }^{1}$ Department of Biochemistry and Molecular Biology, School of Basic Medical Sciences, Capital Medical University, Beijing, China; ${ }^{2}$ Department of Immunology and Pathogen Biology, Liaoning Medical University, Jinzhou, China and ${ }^{3}$ Department of Medical Genetics, School of Basic Medical Sciences, Capital Medical University, Beijing, China

${ }^{*}$ Corresponding author: W Ding, Department of Medical Genetics, School of Basic Medical Sciences, Capital Medical University, 169 room,1st teaching building, 10 You'an Men, Fengtai district, Beijing 100069, China. Tel: +8610 8395 0117; Fax: +8610 8395 1496; E-mail: weiding@ccmu.edu.cn

Keywords: p62/SQSTM1; autophagy; HAMLET; apoptosis; caspase-8

Abbreviations: 3MA, 3-methyladenine; ANS, 8-anilinonaphtalene-1-sulfonic acid; Atg, autophagy-related gene; BAMLET, Bovine $\alpha$-Lactalbumin Made Lethal to Tumor Cells; EBSS, Earle's balanced salt solution; GFP, green fluorescent protein; HAMLET, Human $\alpha$-Lactalbumin Made Lethal to Tumor Cells; HLA, Human $\alpha$-Lactalbumin; LC3, Microtubule-associated protein light chain 3; OA, oleic acid; PMA, primary murine astrocytes; RFP, red fluorescent protein; ROS, reactive oxygen species; SQSTM1, sequestosome 1; UBA, ubiquitin-associated

Received 26.9.12; revised 28.1.13; accepted 05.2.13; Edited by H-U Simon.
} 
In this study, we prepared bioactive HAMLET using recombinant HLA proteins and oleic acids, and then applied it to U87MG glioma cells. We found that HAMLET was able to induce dramatic cell death as well as cellular autophagic responses with substantial alteration of p62/SQSTM1 protein level. By either knockdown or overexpression of p62, the HAMLET-induced cell death was reduced or increased respectively, with accordant changes in caspase-8 activities. The transfection of a p62 deletion mutant showed that the function of $p 62$ to regulate the cell response to HAMLET cytotoxicity was dependent of its UBA domain. Our results indicated that p62/SQSTM1 was an important molecule that is functionally involved in HAMLET-induced cell death. The function of p62/SQSTM1 could be both a sensor and a mediator of the autophagy activation in stressed cells. In addition, p62/SQSTM1 was also able to signal and modulate the dynamics of apoptosis via the caspase-8-dependent pathways.

\section{Results}

Preparation and characterization of HAMLET. HAMLET was prepared with $6 \times$ His-tagged recombinant HLA protein (rHLA) according to the protocol by Kamijima et al. ${ }^{17}$ with minor modifications. Briefly, $\mathrm{Ca}^{2+}$-deprived $\mathrm{rHLA}$ was used instead of the HLA holoproteins. ${ }^{18}$ The same method was applied for the preparation of BAMLET, a HAMLET analog, produced with apo-BLA (bovine $\alpha$-lactalbumin) and oleic acid (OA). The purity of rHLA or HAMLET was analyzed by Coomassie Blue staining following SDS-PAGE ( $A$ in Supplementary Figure 1S), and was also confirmed by mass spectrometry (data not shown). The apo-HLA and HAMLET were able to bind ANS and showed stronger fluorescence, whereas the rHLA or oleic acid could not ( $B$ in Supplementary Figure 1S). The stoichiometry of our produced HAMLET was assayed by BCA method for proteins and ELISA for free fatty acids (FFA). The ratio of HLA protein to oleic acid was determined as $1: 11.5$. The high binding capacity of the apo-HLA with OA in HAMLET was comparable with that reported in other studies. ${ }^{19,20}$

To test the bioactivity for cell death induction of our HAMLET, several cancer cell lines were used in MTS assays. In HeLa cells, the treatment with HAMLET containing $200 \mu \mathrm{g} / \mathrm{ml}$ rHLA (equivalent to $14 \mu \mathrm{mol} / \mathrm{l}$ ) for $6 \mathrm{~h}$ was able to induce the cell death up to $97 \%$, which was at a similar level to that of BAMLET, whereas the treatment with either rHLA or OA alone had little effect (Figure 1a). The same results were observed in U87MG, A549 and H1299 cells, except for primary murine astrocytes (PMA), as shown in Figure 1b. These results indicated that the HAMLET that we had produced exerted the typical functionalities as previously reported..$^{2,21-23}$

HAMLET-induced autophagy in U87MG cells. The high selectivity and efficiency for HAMLET to kill U87MG glioma cells but not PMAs have made it a potential candidate for clinical glioma treatment, where the invasiveness of glioma often causes the coexistence of cancerous and normal tissues. Our MTS results showed that HAMLET we produced could decrease the cell viability of U87MG cells both dose and time dependently (Figures 1c and d). We further explored the mechanisms underlying the effect of HAMLET on U87MG cells. Autophagy was well known to be induced in U87MG cells in response to cytotoxic stimuli, ${ }^{24}$ meanwhile, it was reported that HAMLET could activate autophagy to promote cell death. $^{9}$ Thus, we tested whether HAMLET was able to induce autophagy in U87MG cells, using the GFP-LC3 conversion as the marker of the autophagosomes. The cells with more than three fluorescent puncta were counted as positive for autophagy activation. ${ }^{25}$ We found that $\sim 55 \%$ of GFP-LC3-transfected U87MG cells were observed with autophagy activation after treated with $200 \mu \mathrm{g} / \mathrm{ml}$ HAMLET for $3 \mathrm{~h}$ (Figures $1 \mathrm{e}$ and $\mathrm{f}$ ). HAMLET-induced autophagy was confirmed by electron microscopy, where double-membrane autophagosomal vacuoles were identified (Figure 1g, white arrows). The conversion from LC3 I to LC3 II upon HAMLET treatment was also analyzed with western blot (Figures $2 a$ and b). Meanwhile, the protein level of p62/SQSTM1 was also detected. p62/SQSTM1 was a polyubiquitin-binding scaffold protein in autophagosomes and known to bind to LC3 and facilitate the autophagy degradation of ubiquitinated protein aggregates. ${ }^{26}$ We found that HAMLET treatment of U87MG cells for short periods significantly increased the p62 protein level (Figures $2 a$ and b). The immunofluorescence assays further demonstrated that the colocalization of p62 with LC3 puncta was also intensified (Figure 2c).

Modulation of autophagy in U87MG cells altered HAMLET-induced cell death with changes of p62/ SQSTM1 at protein levels. To explore whether autophagy is functionally involved in HAMLET-induced cytotoxicity, we used various reagents to either activate or inhibit the autophagy process in U87MG cells. The knockdown of Atg5 with RNA interference increased the protein level of p62 and decreased the cell viability by a maximum of $13 \%$ under HAMLET treatment of $200 \mu \mathrm{g} / \mathrm{ml}$ (Figures $3 \mathrm{a}$ and b). The inhibition of autophagy with 3MA increased the p62 level and reduced cell viability by $14 \%$ and $40 \%$ when treated with 100 and $200 \mu \mathrm{g} / \mathrm{ml}$ HAMLET, respectively (Figures 3c and $\mathrm{d}$ ). The activation of autophagy with EBSS starvation, however, decreased the cell viability by $63 \%$ with $200 \mu \mathrm{g} / \mathrm{ml}$ HAMLET with a mild increase of p62 (Figures $3 e$ and f). The activation of autophagy with $2.5 \mu \mathrm{mol} / \mathrm{l}$ rapamycin reduced the p62 level and increased the cell viability $12 \sim 16 \%$ in the presence of various doses of HAMLET (Figures $3 g$ and $h$ ). These results suggested that autophagy mostly had a protective role in HAMLET-induced cell death, with the exception of EBSS treatment. As the regulatory and participating factors of autophagy was known to be complex, therefore merely determining the extent of HAMLET-induced cell death according to the current known marker proteins of autophagosomes might not be sufficient. Interestingly, the p62 level changes in HAMLET-treated cells correlated with the degrees of LC3 conversion in most cases. In fact, the dynamic changes of p62 levels could be more rapid and significant, which suggested that p62 could be functionally involved or at least could be used as a indicating factor of HAMLET-induced cell death. 

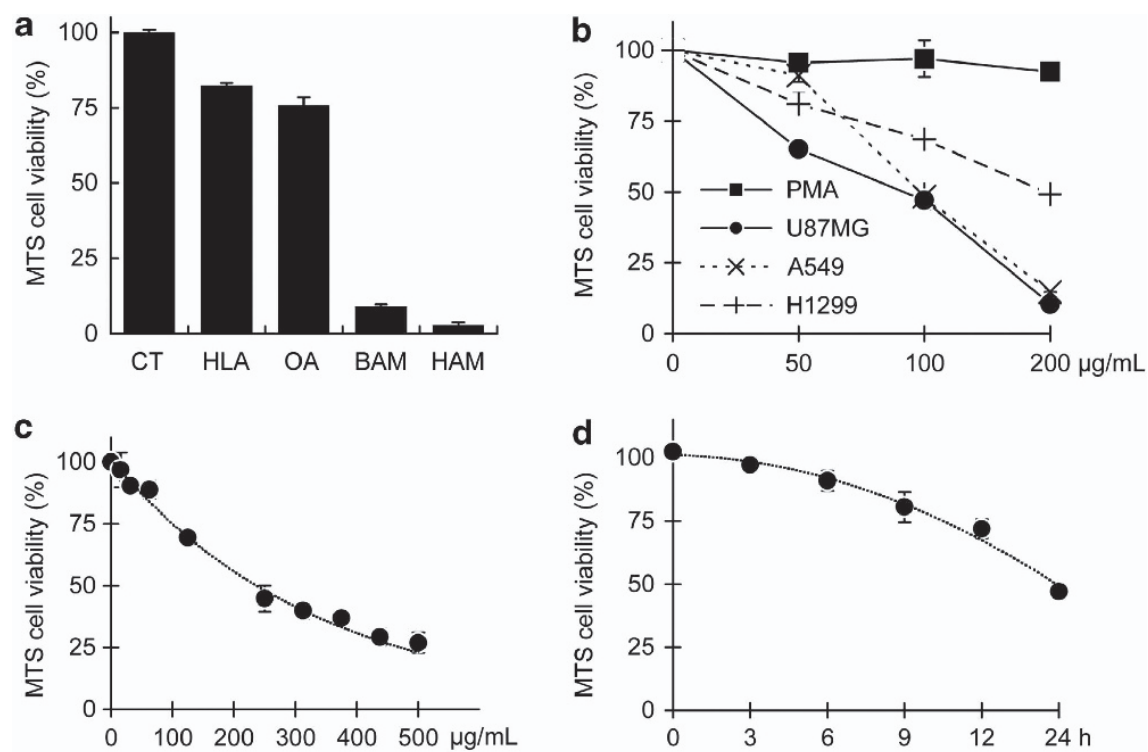

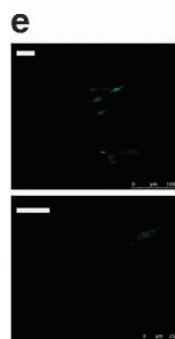

0

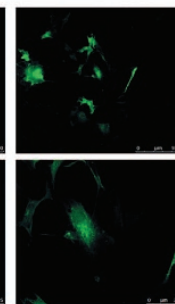

100

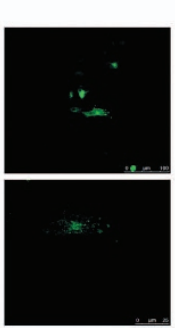

$200 \mu \mathrm{g} / \mathrm{mL}$

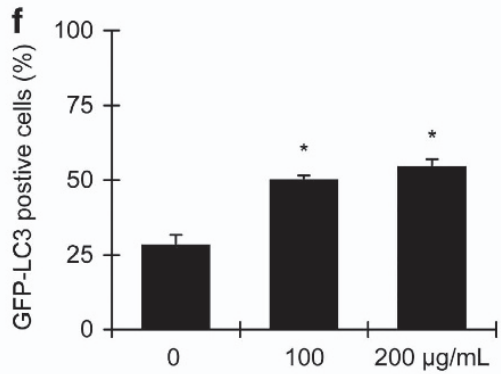

g

HAM $(200 \mu \mathrm{g} / \mathrm{mL})$

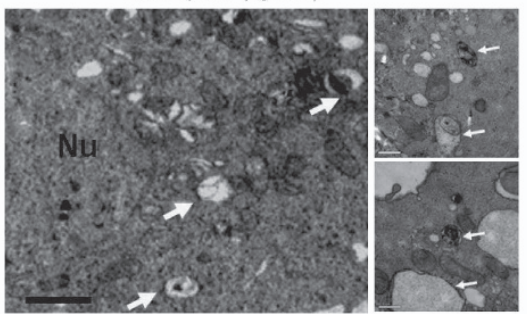

Figure 1 HAMLET treatments induced cancer cell death and caused autophagic response in U87MG cells. (a) HAMLET was able to induce massive cell death in HeLa cells. The cells were treated with $200 \mu \mathrm{g} / \mathrm{ml} \mathrm{HAMLET}$ for $6 \mathrm{~h}$ and then subjected to MTS assay. The effects of BAMLET (HAMLET derivative of bovine $\alpha$-lactalbumin) and apoHLA or oleic acid treatment alone were also tested. (b) U87MG cells were sensitive to HAMLET treatment in a dose-responsive manner. Cancer cell lines of H1299, A549 and non-transformed primary murine astrocytes (PMA) were treated with HAMLET for $24 \mathrm{~h}$, and subjected to MTS assays for cell viability. The data were normalized to the control group and presented as mean \pm S.E.M. from five independent experiments. (c and $\mathbf{d})$ The dose-dependent $(12 \mathrm{~h})$ and time course responses $(100 \mu \mathrm{g} / \mathrm{ml})$ of $\mathrm{U} 87 \mathrm{MG}$ cells following HAMLET treatments were determined by MTS assays. (e and f) HAMLET treatments (100 $\mu \mathrm{g} / \mathrm{ml}$ ) for $3 \mathrm{~h}$ induced GFP-LC3 aggregation in transfected U87MG cells. From the confocal images in each sample, a random 50 GFP positive cells were analyzed for the percentage with at least three aggregated GFP-LC3 spectacles as positive for autophagy. (g) TEM microscopy of U87MG cells with $3 \mathrm{~h}$ treatments of $100 \mu \mathrm{g} / \mathrm{ml}$. The autophagosomes or autolysosome-like structure were indicated at the white arrows $($ scale $=1 \mu \mathrm{m})$. On the right side panel were images with higher magnifications $($ scale $=0.5 \mu \mathrm{m})$

Modulation of the p62/SQSTM1 expression was able to change the sensitivity of U87MG cells to HAMLET cytotoxicity. To investigate whether p62 was functionally involved in HAMLET-induced cell death beyond just serving as a marker for autophagy activation, we used both the p62 overexpression and knockdown approaches in U87MG cells, and evaluated the cell viability after HAMLET treatment. As shown in Figures $4 a$ and $b$, the knockdown of p62 reduced the sensitivity of U87MG cells to HAMLET, whereas the overexpression of p62 increased the cytotoxicity of HAMLET (Figures 4c and d). As other reports have shown that p62 could form aggregates in response to multiple hazardous stimuli and mediated cell death, ${ }^{11,27}$ we quantified aggregated p62 puncta by introducing a GFP-tagged p62 into U87MG cells. A significant increase of aggregated p62 was observed upon HAMLET treatment (Figures $4 \mathrm{e}$ and $\mathrm{f}$ ). Together with the increase of aggregated p62 puncta colocalized with the autophagic LC3 (Figure 2c), the data 

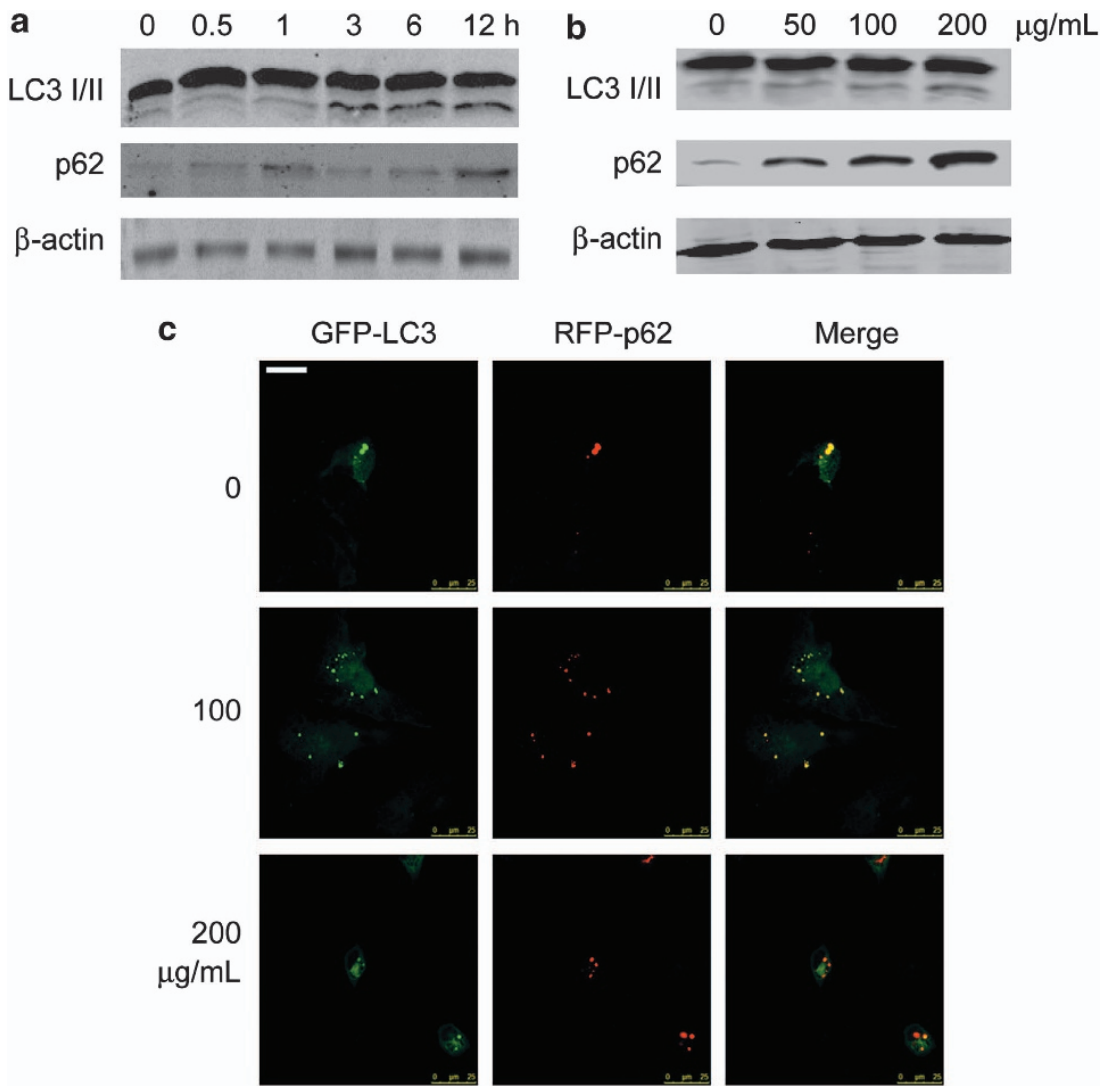

Figure 2 HAMLET induced autophagic response in LC3 protein levels and localization was associated with the changes of p62/SQSTM1. (a and $\mathbf{b})$ The dose-dependent $(1.5 \mathrm{~h})$ and time course $(100 \mu \mathrm{g} / \mathrm{ml})$ analyses of the autophagy marker LC3 I/ll protein level were compared with those of p62/SQSTM1 by western blot. (c) Cellular localization of GFP-LC3 and RFP-p62 in U87MG cells treated with HAMLET $100 \mu \mathrm{g} / \mathrm{ml}$ for $3 \mathrm{~h}$ by confocal microscopy (scale $=25 \mu \mathrm{m}$ )

indicated that HAMLET-induced p62 aggregation might functionally mediate the HAMLET-induced cell death in glioma cells.

HAMLET induced caspase-8 mediated apoptosis in U87MG cells. Apopoptosis was extensively described in earlier HAMLET studies. To address if the p62/SQSTM1 function in autophagy is connected with cell apoptosis, we first used calcein-AM staining to dynamically monitor the HAMLET-induced cell death semi-quantificatively. We found that massive cell death started between $6-12 \mathrm{~h}$ of HAMLET treatment (Figures $5 a$ and $b$ ). The results from the TUNEL experiments using $100 \mu \mathrm{g} / \mathrm{ml}$ HAMLET for $12 \mathrm{~h}$ showed that intense cell apoptosis indeed occurred (Figures $5 c$ and d). The regulation of apoptosis mostly involved the activities of two different types of caspases, where caspase- 8 and caspase-9 were believed to initiate diverged pathways. Recent studies suggested that caspase-8 was colocalized with p62 and its full activation seemed to crosstalk with autophagy. ${ }^{28}$ Therefore, we started to investigate the activation of caspase-8 following HAMLET treatment. The results showed that caspase-8 activation occurred prior to the HAMLET-induced cell death (Figure $5 \mathrm{e}$ ). We further employed caspase-8 inhibitor AC-LETD-CHO or pan-caspase inhibitor Z-VAD-FMK, and found that the caspase-8 inhibitor effectively attenuated HAMLET-induced cell death to the similar level as that of the pan caspase inhibitor. This suggested that caspase- 8 appeared to be the predominant type of caspase in mediating HAMLET-induced apoptosis (Figure $5 \mathrm{f}$ ). In addition, we analyzed the level of caspase-8 active components, subunit $\mathrm{p} 18$, and cleaved caspase-9, and found that $p 18$ correlated with the increase of p62 much more significantly than with that of p62 and cleaved caspase9 (Figure $5 \mathrm{~g}$ ), which was also consistent with the connection to autophagy activation, as shown in Supplementary Figure S2. We verified the results by comparing the activity of caspase- 8 with that of caspase- 9 . As expected, caspase-8 manifested much more significant activation than caspase-9 in response to HAMLET treatment (Figure $5 \mathrm{~h}$ ).

p62/SQSTM1 mutant with UBA domain deletion attenuated HAMLET-induced cell death. Recent report demonstrated that caspase-8-mediated apoptosis involved the polyubiquitination and aggregation of caspase- 8 for its full activation. $^{29}$ The UBA domain at the C-terminus of $\mathrm{p} 62 /$ SQSTM1 was suggested to be a key domain to bind and recruit ubiquitinated proteins, including polyubiquitinated caspase-8. We constructed an overexpression plasmid of p62 mutant with the deletion of its UBA domain and tagged with GFP. When transfected into the U87MG cells and compared with the wild type p62, we found that the UBAdeleted p62 largely abolished the ability to form intracellular 
a

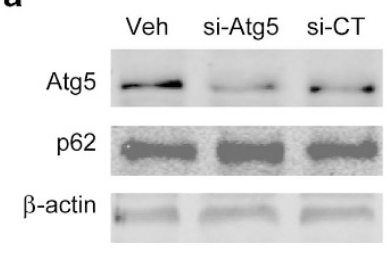

C

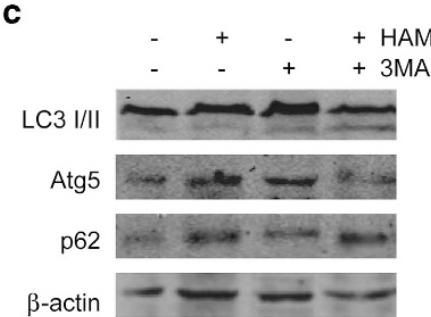

e

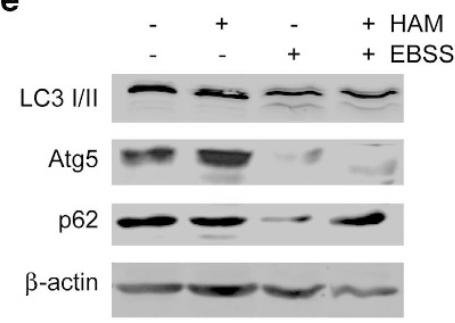

g

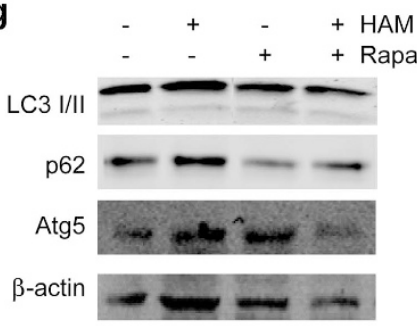

b

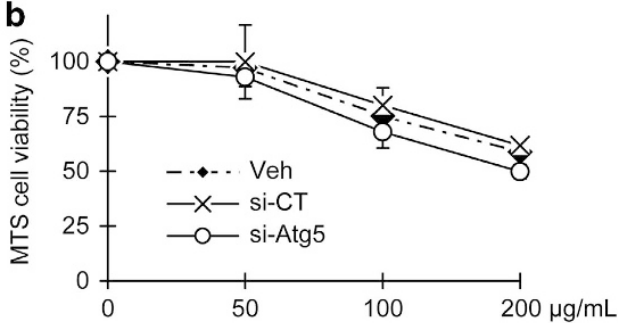

d

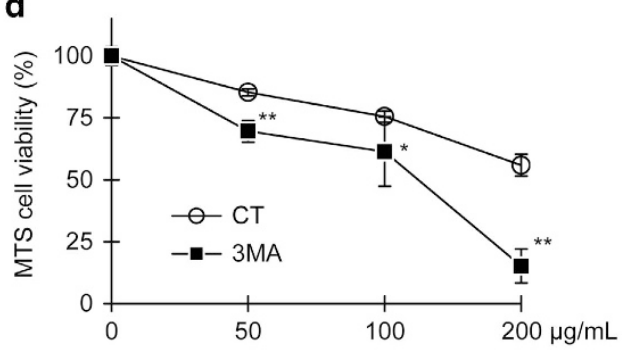

f

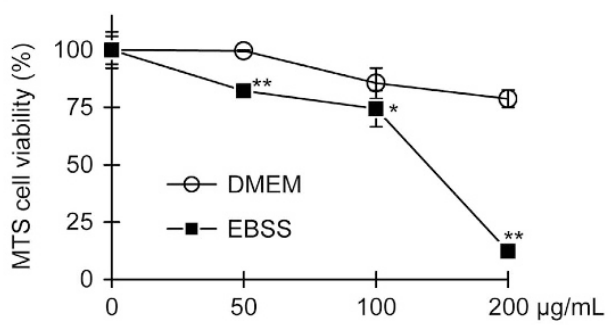

h

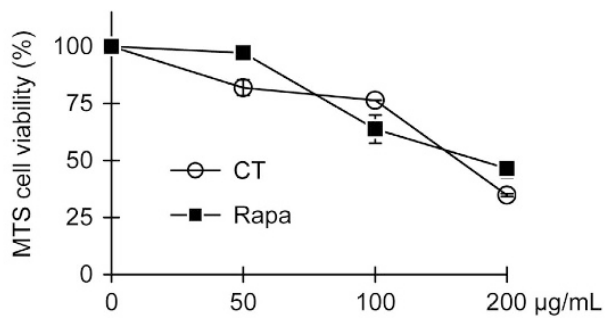

Figure 3 Activation or inhibition of autophagy influenced HAMLET-induced cell death and associated with changes of p62 protein levels. (a and $\mathbf{b}$ ) U87MG cells were transfected with a pSUPER-si-Atg5 plasmid for $60 \mathrm{~h}$. (c to h) U87MG cells were treated with autophagy inhibitor of $3 \mathrm{MA}$ at $5 \mathrm{mmol} / \mathrm{l}$, autophagy-inducing EBSS medium, or autophagy activator rapamycin at $2.5 \mu \mathrm{mol} / \mathrm{l}$ for $3 \mathrm{~h}$. The cells were then exposed to $100 \mu \mathrm{g} / \mathrm{ml} \mathrm{HAMLET}$ in DMEM with $10 \% \mathrm{FBS}$ or EBSS without serum. The protein levels of LC3 I/II, Atg5 and p62 were determined by western blot. The cell viability was assayed by MTS at $12 \mathrm{~h}$. The results were normalized and presented as mean \pm S.E.M. from five independent experiments. ${ }^{*} P<0.05,{ }^{* *} P<0.01$

aggregates (Figure 6b). The HAMLET-induced cell death could be significantly reduced by transfection of GFPp62 ${ }^{\triangle U B A}$ (Figure $6 c$ ), as well as the caspase-8 cleavage and p18 production (Figure 6d).

\section{Discussion}

HAMLET is an attractive agent that is able to kill cancer cells selectively but not non-transformed cells. The induction of cell apoptosis with HAMLET treatments had been reported in previous studies, ${ }^{1,21,23,30,31}$ where non-canonical apoptotic responses were often observed, such as less association with caspase-3, caspase-9, Bcl-2 and p53 activities. ${ }^{8}$ Therefore, the search for alternative cell death-related pathways or mechanisms is the current focus in HAMLET studies, where autophagy is an important cellular candidate process to be considered. However, the exact role of autophagy in HAMLET-induced cytotoxic activity remained to be obscure. Earlier reports have shown that autophagy had a critical role in druginduced cell death in U87MG cells. ${ }^{32}$ The findings of HAMLET aggregation and its localization in lysosome-like structures ${ }^{33}$ prompted us to investigate the role of autophagy in HAMLETinduced cell death.

In our study with U87MG cells, we discovered that autophagy was indeed activated following HAMLET treatment, as shown by the occurrence of intracellular puncta of fluorescent GFP-LC3, as well as by the typical morphological structures identified in TEM. The results agreed with the 
a
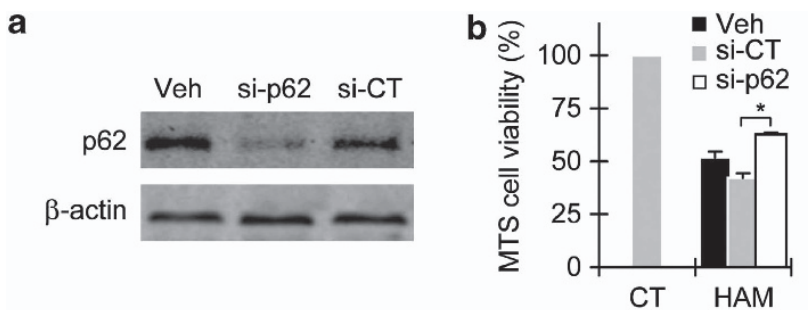

C
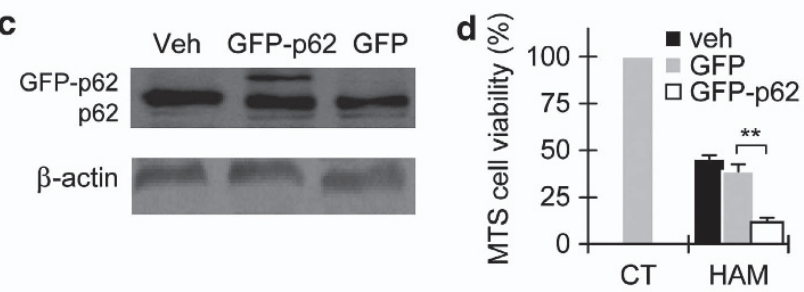

e
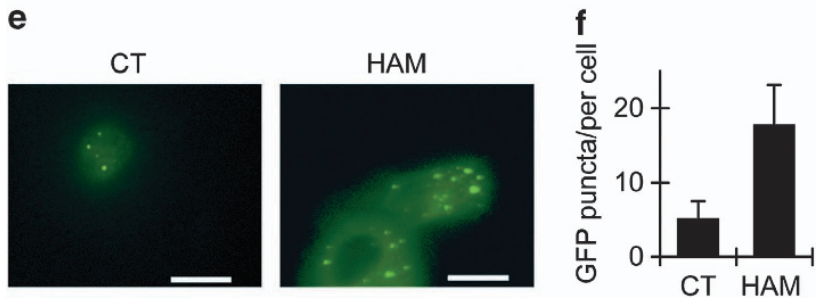

Figure 4 HAMLET-induced cytotoxicity could be regulated through the modulation of p62/SQSTM1 protein. (a and $\mathbf{b}$ ) Transfection of siRNA targeted to p62/SQSTM1 for $72 \mathrm{~h}$ reduced the cell death in U87MG cells after $100 \mu \mathrm{g} / \mathrm{ml}$ HAMLET treatment for $12 \mathrm{~h}$. (c and d) Overexpression of p62/SQSTM1 for $24 \mathrm{~h}$ increased HAMLET-induced cell death. (e and f) HAMLET increased the formation of cellular aggregates of $\mathrm{p62/SQSTM1}$ proteins. U87MG cells were transfected with GFP-p62 for $24 \mathrm{~h}$, and then treated with $200 \mu \mathrm{g} / \mathrm{ml}$ HAMLET for $1.5 \mathrm{~h}$. The GFP-p62 aggregates identified as the green fluorescent puncta were counted from 5 or more representative images $($ scale $=50 \mu \mathrm{m})$ and averaged to numbers per cell. ${ }^{*} P<0.05,{ }^{* *} P<0.01$

previous finding in MDA-MB-231 cells, ${ }^{9}$ where increased LC3 foci were discovered in autophagosomes after HAMLET treatment. We further analyzed the role of autophagy in HAMLET cytotoxicity. The results showed that the inhibition of autophagy accelerated the HAMLET-induced cell death, whereas the activation of autophagy with rapamycin exposure attenuated the cytotoxicity. There is growing evidence supporting that autophagy serves as a protective mechanism for cells to respond to various stress. ${ }^{34-37}$ In many cases, the increased levels of autophagy markers that correlated to the cell death did not necessarily reflect the degree of autophagy activation, but rather as an indication of the exhaustion or failure of the autophagy machinery, which led to the abnormal accumulation of these proteins. Similar conclusions from series of studies might be helpful in understanding the response of different cell types to autophagy-inducing reagents, including HAMLET ${ }^{38,39}$ Although the activation of autophagy is a protective response for cells to adapt to hazardous environments in general, HAMLET-induced cell death was enhanced in U87MG cells with starvation-induced autophagy. Earlier report also showed that HAMLET-induced autophagy might increase the cell death in A549 cells. ${ }^{9}$ We believed that the early autophagy response was likely to serve as a protective mechanism for cells to respond to HAMLET treatment, but long-term autophagy activation could stress the cells and exhaust the protective machinery, then eventually lead to increased sensitivity to cytotoxins. Besides, autophagy is an extremely sophisticated system that can be activated through different signal pathways and involves numerous factors. Therefore, the role of autophagy in the cellular response to HAMLET can be complicated and deserves future extensive investigation. An interesting finding from this study was that the protein level changes of p62/SQSTM1 seemed to respond more rapidly and correlated better to the outcome of HAMLET-induced cell death than LC3.

p62/SQSTM1 is an autophagy-related protein and is normally degraded by the lysosomal proteases through the interaction with LC3 II. ${ }^{40}$ It was recently found that p62 functioned as a multi-functional protein at a critical decision point to control cell death or survival. ${ }^{11}$ The overexpression of p62 contributed to ROS production in a positive feedback loop, thereby leading to increased genome instability. ${ }^{41}$ Other reports showed that p62 was able to maintain and stabilize the integrity and functions of mitochondria for the longevity or immortalization of mammalian cells. ${ }^{42}$ The accumulation of p62 reflected the inhibition of proteasomal activities, ${ }^{43}$ also seen in Supplementary Figure S2 and S3. In U87MG cells, we discovered that the changes in p62 levels and its cellular aggregation correlated with the activation of autophagy, and could be used as an indicator for cell viability after HAMLET treatments, or maybe even for drug sensitivity.

Recent reports demonstrated that $\mathrm{p} 62$ provided a signalorganizing interface to recruit poly-ubiquitinated caspase-8 and subsequently allow its full activation. When treated with reagents that induced ER stress or proteaosome inhibition, the cells could activate the apoptosis system directly through caspase-8, without the involvement of death receptor signaling. ${ }^{44}$ This novel mechanism of caspase-8mediated apoptosis was dependent on the autophagy-related proteins LC3 and p62. ${ }^{28,45}$ Thus, in addition to serving as a typical caspase species in the 'classic' extrinsic apoptosis, caspase-8 can also be activated in a p62-dependent manner and involved in an alternative endogenous pathway of apoptosis, especially when induced by various reagents or drugs. We postulate that the HAMLET-induced caspase-8 activation relied on the protein components of HAMLET within the complex, although OA might also be essential to the cytotoxicity of HAMLET. ${ }^{46}$

The UBA domain of the p62 protein at the C-terminus was known to be essential to allow p62 to interact with ubiquitinated proteins, through which p62 may recruit and oligomerize important signaling molecules into cytosolic speckles. ${ }^{11}$ In our study, a UBA-deleted p62 mutant was found to reduce the ability of promoting HAMLET-induced cell death, as well as the activity to form intracellular aggregates. However, p62/ SQSTM1 binding to caspase-8 did not seem to control the levels of procaspase-8 or other cell death-related proteins in activated T cells. ${ }^{47}$ Compared with the increase of p62, less accumulation of UBA-deleted p62 following HAMLET treatment might be due to the accelerated autophagic degradation, as mutant p62 lost the ability to transport the ubiquitinated protein to the proteasome system. These findings provided additional details concerning the roles of 
a

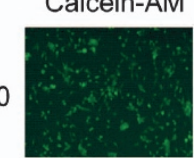

3

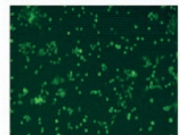

6

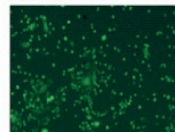

$12 \mathrm{~h}$

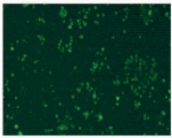

b

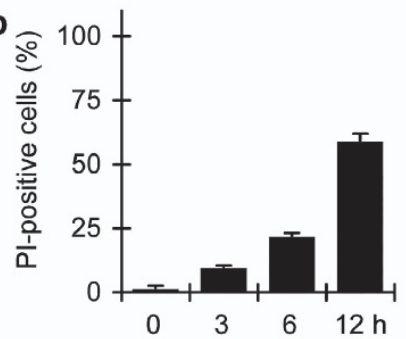

e

$\begin{array}{lllllll}0 & 0.25 & 0.5 & 1 & 3 & 6 & 12 \mathrm{~h}\end{array}$

Casp8(p18)

$\beta$-actin

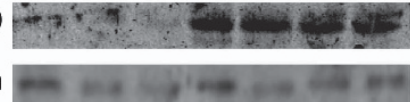

g
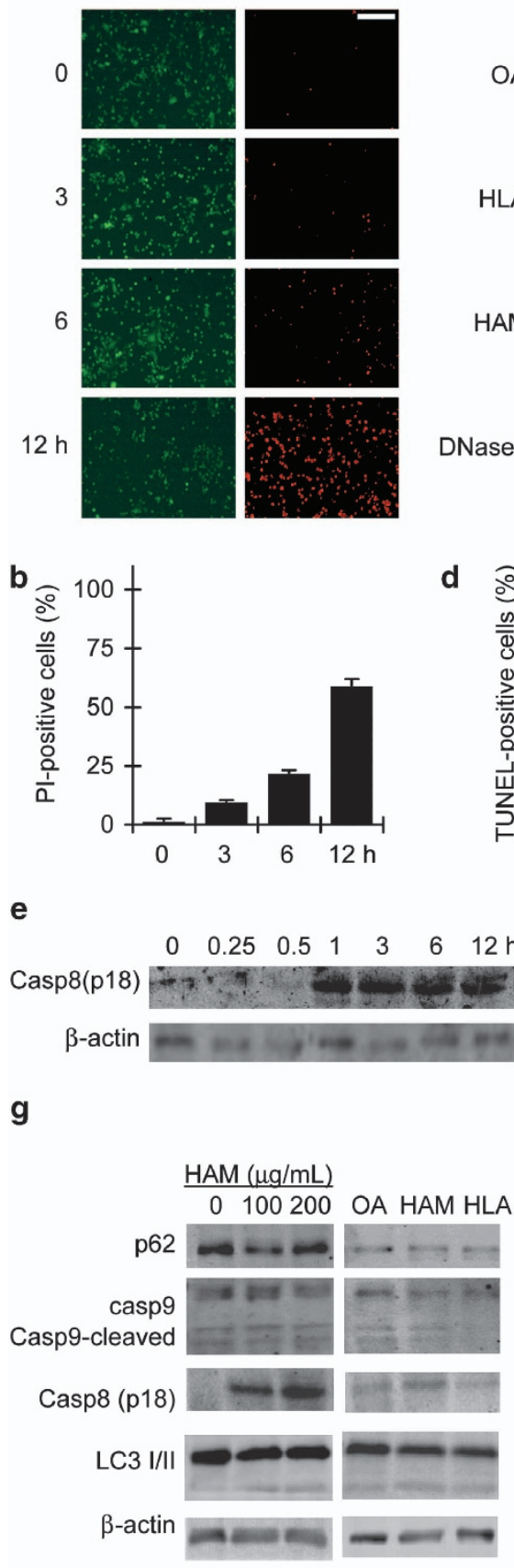

d
DNase I

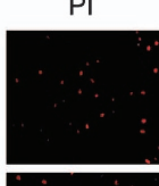

TUNEL

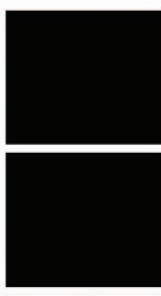

Merge

HAM
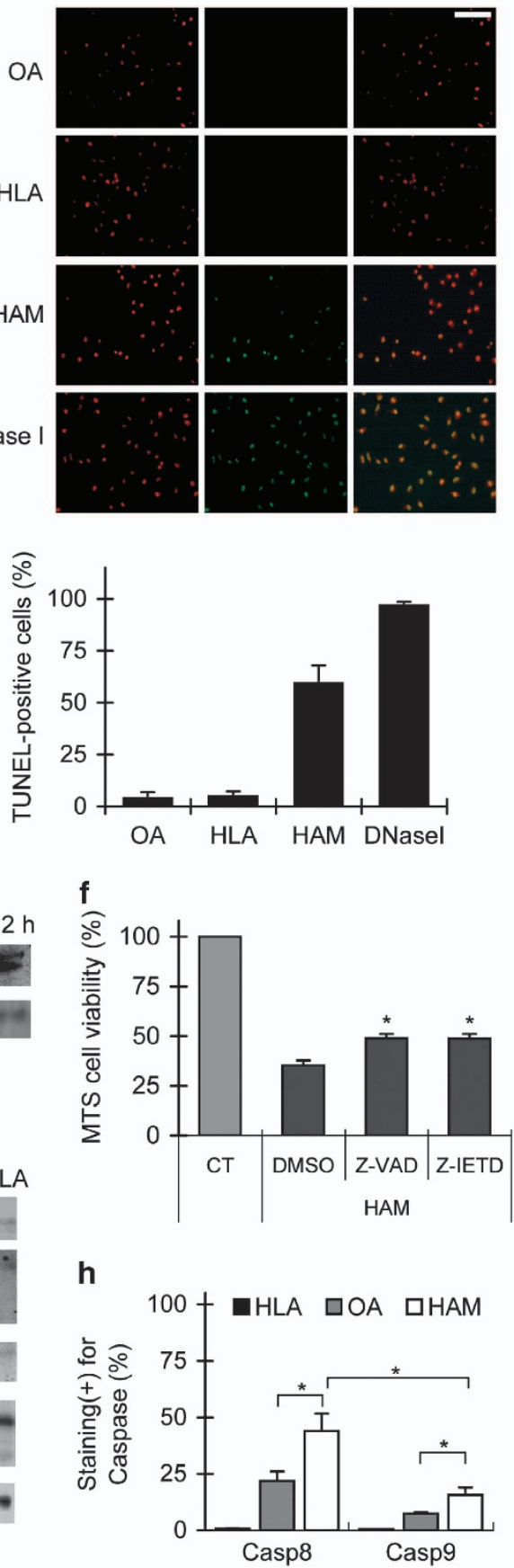

Figure 5 HAMLET-induced apoptosis was more relevant to caspase-8 activation than caspase-9. (a) The time course of $100 \mu \mathrm{g} / \mathrm{ml}$ HAMLET-induced cell death in U87MG cells by calcein-AM/PI staining. (b) Quantification of A. Data was shown as the averaged percent of apoptotic cells \pm S.E.M. from three independent experiments by counting a total of 200 cells. (c) The levels of apoptosis in U87MG cells treated with $100 \mu \mathrm{g} / \mathrm{ml} \mathrm{HAMLET,} 100 \mu \mathrm{g} / \mathrm{ml} \mathrm{HLA}$ or $210 \mu \mathrm{M}$ OA for $12 \mathrm{~h}$ as determined by TUNEL assays with quantification. Fluorescence images were acquired under $10 \times$ magnification. (d) The counts of apoptotic cells were presented as mean \pm S.E.M. of a total of 100 cells in each condition from three independent experiments. (e) The time course of the activated caspase-8 p18 levels by western blot of U87MG cells treated with $100 \mu \mathrm{g} / \mathrm{ml}$ HAMLET. (f) The MTS cell viability of U87MG cells treated with $100 \mu \mathrm{g} / \mathrm{ml}$ HAMLET for $12 \mathrm{~h}$ with pretreatments of pan-caspase (z-VAD-FMK) or caspase-8 (AC-IETD-CHO) inhibitors for $30 \mathrm{~min}$. (g) The western blot of caspase-9 and caspase-8 activation in U87MG cells treated with $100 \mu \mathrm{g} / \mathrm{ml}$ HAMLET or $210 \mu \mathrm{M} \mathrm{OA} \mathrm{for} 3 \mathrm{~h}$. The protein levels of caspase-8 p18, cleaved caspase-9, p62 and LC3 I/ll were detected. (h) The activities of caspase-8 and caspase-9 were compared following $100 \mu \mathrm{g} / \mathrm{ml} \mathrm{HAMLET} \mathrm{treatment} \mathrm{for}$ $3 \mathrm{~h}$. The cells were preloaded with FAM-LETD-FMK (caspase-8 fluorescent substrate) or FAM-LEHD-FMK (caspase-9 fluorescent substrate) at $37^{\circ} \mathrm{C}$ for $60 \mathrm{~min}$. The numbers of positively stained cells were counted and shown as the averaged percentage \pm S.E.M. from three independent experiments

p62 in HAMLET-induced cellular response, and meanwhile, suggested that p62-associated cell death or survival might be closely related to the ubiquitination process of proteins.
The discovery of the involvement of p62/SQSTM1 in caspase-8-related HAMLET-induced cell death started to widen our understanding of the mechanism for 


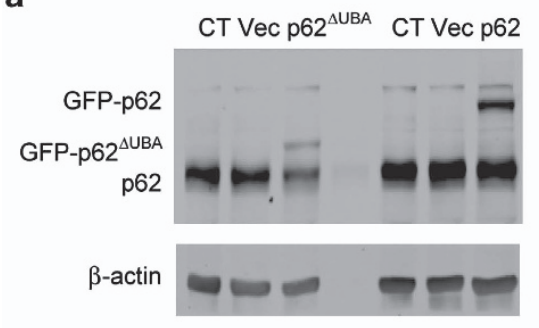

b

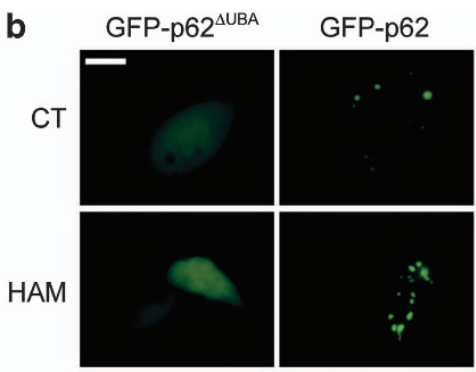

c

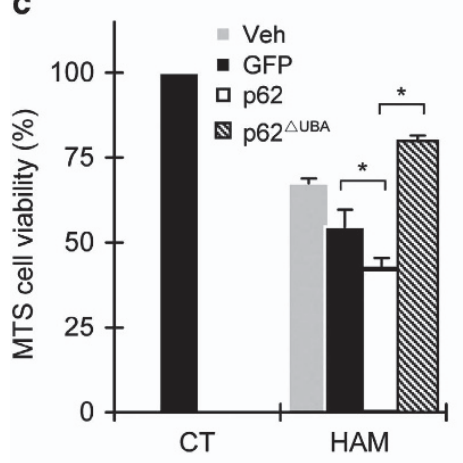

d

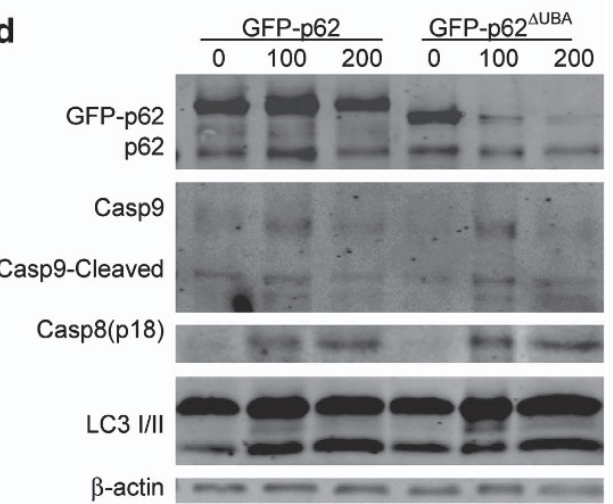

Figure 6 HAMLET-induced caspase-8 activation was modulated by p62/SQSTM1 and depended on its C-terminus UBA domain. (a) Western blot of U87MG cells transfected with the GFP fusion of wild-type or mutant p62/SQSTM1. (b) The p62/SQSTM1 UBA-deletion mutant was unable to form aggregated fluorescent speckles in U87MG cells. Cells were transfected for $24 \mathrm{~h}$, and then exposed to $200 \mu \mathrm{g} / \mathrm{ml} \mathrm{HAMLET}$ for $1.5 \mathrm{~h}$ before photographed. (c) Transfection of p62/SQSTM1 mutant attenuated the HAMLET-induced cytotoxicity. U87MG cells were transfected with GFP-p62 or GFP-p62 ${ }^{\text {AUBA }}$ for $24 \mathrm{~h}$ and assayed by MTS after $12 \mathrm{~h}$ exposure in $200 \mu \mathrm{g} / \mathrm{ml}$ HAMLET. The results were presented as mean \pm S.E.M. from three independent experiments. ${ }^{*} P<0.05$. (d) Western blot for the comparison of caspase-8 activation following GFP-p62 and GFP-p62 ${ }^{\triangle U B A}$ transfection. After transfection for $24 \mathrm{~h}$, the protein levels of caspase-8 p18, cleaved caspase-9, p62 and LC3 I/II from $3 \mathrm{~h} \mathrm{HAMLET-treated} \mathrm{U87MG} \mathrm{cells} \mathrm{were}$ detected by western blot

HAMLET-induced cell death. HAMLET, in essence, may be regarded as a form of misfolded protein, and was able to directly inhibit the 205 proteasome activity. ${ }^{7}$ Increasing evidence has shown that proteasome inhibition could induce the activation of autophagy, either for cell protection or to promote cell death. ${ }^{48}$ We also found that HAMLET treatments induced both the activation of autophagy and inhibition of proteasome (Supplementary Figures S2 and S3). The crosstalk between autophagy and apoptosis occurs in HAMLETinduced cell death with $\mathrm{p} 62$ as a possible conjunction point for the related processes. We found that the p62 protein level correlated with the activation of caspase-8. Considering that autophagosomal membrane may serve as the scaffold interface for the clustering and activation of intracellular caspase- $8,{ }^{28}$ it is plausible that ubiquitinated caspase- 8 might directly interact with $\mathrm{p} 62$ at the autophagosomes during the induction of autophagy by HAMLET treatments.

Further investigations regarding the relationship between the ubiquitin-proteasome system and autophagy are worthwhile for the clarification of some unsettled questions. For example, whether the p62 stability is regulated for the determination of its protein levels, and how is it connected with the balance between autophagy and proteasome pathway? In any of these studies, HAMLET could be used as a useful reagent to dissect the role of autophagy activation in cell fate determination. Moreover, HAMLET variants or HAMLET-like complex ${ }^{33}$ may exist in certain physiological or pathological conditions, for incidence, the $\beta$-amyloid aggregates in Alzheimer disease. ${ }^{49}$ Thus, from a broader perspective, the future studies in HAMLET-induced cell death may not only benefit for developing its application for cancer therapies, but also may help to understand the pathogenesis for certain autophagy-related diseases.

\section{Materials and Methods}

Cell culture and transfection. HeLa, A549, H1299 and U87MG cells were purchased from the cell bank at Peking Union Medical University. U87MG and HeLa cells were cultured in Dulbecco's modified Eagle's medium (DMEM) with high glucose (Hyclone, Beijing, China) supplemented with $10 \%$ fetal bovine serum (FBS, Sijiqing, Zhejiang, China). A549 and H1299 cells were cultured in RPMI1640 (Hyclone) containing 10\% FBS. Primary cultures of cerebral cortical astrocytes were prepared from day 1 newborn $\mathrm{C} 57 \mathrm{BL} / 6 \mathrm{~N}$ mice, according to the method by Tanaka et al., ${ }^{50}$ and maintained in 10\% FBS DMEM supplemented with $100 \mathrm{U} / \mathrm{ml}$ penicillin and $0.1 \mathrm{mg} / \mathrm{ml}$ streptomycin. The obtained cells were used at day 14 after removing the oligodendrocytes by vigorously shaking the culture flask and changing the medium for several rounds. Fugene HD reagent (Roche, Penzberg, Germany) was used for cell transfection following the manufacturer's standard protocols.

Plasmids, chemical reagents and antibodies. The GFP-p62 plasmid was kindly provided by Dr. Terje Johansen (University of Tromsø, Tromsø, Norway). The GFP-LC3 plasmid was provided by professor Ying-Yu Chen (Peking University, Heath Science Center, Beijing, China). A GFP-p62 ${ }^{\triangle U B A}$ plasmid was constructed by using CCGCTCGAGATGGCGTCGCTCACCGTGAAGGCCT and CCGGAATTCTCATGGCGGGAGATGTGGGTACAAG as PCR primers, and Xhol and $E c o R$ the restriction sites. For the RFP-p62 plasmid, the full-length human p62 was amplified using CTGGCGTCGCTCACCGTGAAGGCCT and CGGAATTC TCACAACGGCGGGGGATGCTTTG as primers, and cloned into a pDsRED2C1 vector by $B g l l$ and EcoRI restriction sites. A pSUPER-siAtg5 plasmid was 
constructed by inserting the targeting sequences $5^{\prime}$-GCAACTCTGGATGGGA TTG- $3^{\prime}$ of Atg5 into the pSUPER-basic vector by Bgll and Hindlll restrictions. The human $\alpha$-LA (HLA) was amplified from a MCF-7 cell cDNA library using primers of GGGAATTCCATATGAAGCAATTCACAAAATGTGAGCTG and CCGCTCGA GCAACTTCTCACAAAGCCACTGTTCC, then cloned into a pET 30a $(+)$ vector using Ndel and Xhol sites. All plasmids used in this study were confirmed by DNA sequencing.

Bovine $\alpha$-lactalbumin, 3-methyladenine (3MA), MG132, rapamycin were purchased from Sigma-Aldrich (St. Louis, MO, USA). Earle's balanced salt solution (EBSS) was purchased from HyClone. AC-IETD-CHO, z-VAD-FMK, FAM-LETDFMK, and FAM-LEHD-FMK were purchased from Biomol (Biomol. Hamburg, Germany). Antibodies of rabbit anti-LC3 or p62 (Sigma), mouse anti-actin (ZhongShan GoldenBridge Biotechnology, Beijing, China), rabbit anti-Atg5, mouse anti-caspase-9 (Cell signaling technology, Danvers, MA, USA), mouse anti-Ub and anti-caspase-8 (p18) (P4D1) (Santa Cruz Biotechnology, Santa Cruz, CA, USA) were applied following the manufacturer's recommendation.

HAMLET preparation. The HAMLET (rHLA-OA complex) or BAMLET (BLA-OA complex) for this study were prepared according to the method described by Kamijima et al. ${ }^{17}$ Briefly, oleic acid (Sigma-Aldrich) stock was dissolved in ethanol to make $210 \mathrm{mM}$ stock in $20 \mathrm{mM}$ Tris- $\mathrm{HCl}(\mathrm{pH}$ 8.0) under sonication. Recombinant HLA protein with $6 \times$ HIS tag was purified by affinity chromatography TALON resin (GE Healthcare, Buckinghamshire, UK). Recombinant HLA protein or BLA was decalcified with $1 \mathrm{mM}$ EDTA/20 mM Tris- $\mathrm{HCl}$ (pH 8.0) at $4{ }^{\circ} \mathrm{C}$ overnight and diluted to $14 \mu \mathrm{mol} / /$, and then mixed with $\mathrm{OA}$ stock solution (in a1:15 molar ratio) at $60^{\circ} \mathrm{C}$ for $10 \mathrm{~min}$ and cooled to room temperature. Excess oleic acids were carefully removed by centrifugation. The product was isolated and concentrated to $2 \mathrm{mg} / \mathrm{ml}(140 \mu \mathrm{mol} / \mathrm{l})$ using Centrifugal Filter Devices (Millipore, Billerica, MA, USA).

The obtained products were characterized by 8-anilinonaphtalene-1-sulfonic acid (ANS) (Sangon Biotech, Shanghai, China) spectra analyses using a Spectra Max M2 spectrophotometer (Molecular Devices, Sunnyvale, CA, USA) with the bandpass setting of $5 \mathrm{~nm}$. ANS was known to bind to HAMLET, and caused a emission spectra change between 380 and $580 \mathrm{~nm}$, with excitation at $365 \mathrm{~nm}$. The HAMLET or BAMLET aliquot was filtered and stocked at $-80^{\circ} \mathrm{C}$. The complex was heated for $10 \mathrm{~min}$ at $60^{\circ} \mathrm{C}$ before usage.

Cell viability and apoptosis assays. The cell viability after HAMLET treatment was determined using the CellTiter-96 Aqueous-One Solution Cell Proliferation (MTS) Assay kit (Promega, Madison, WI, USA). The cells were seeded in 96-well plates at $0.5 \sim 1 \times 10^{4}$ cells per well for $24 \mathrm{~h}$ and then treated with HAMLET of necessary conditions according to the experimental design. The MTS reagents were applied for $1 \mathrm{~h}$ at $37^{\circ} \mathrm{C}$, and the plates were subjected to measures at $490 \mathrm{~nm}$ with a Synergy HT Multi-Mode Microplate Reader (BioTek, Winooski, VT, USA).

The cells after HAMLET treatments were incubated with $1 \mu \mathrm{g} / \mathrm{ml}$ Calcein-AM (Invitrogen, Eugene, OR, USA) and $10 \mu \mathrm{g} / \mathrm{ml}$ propidium iodide (PI, Invitrogen) for $30 \mathrm{~min}$ at $37^{\circ} \mathrm{C}$. A double-blinded cell counting was performed for live (green) and dead cells under a DMIRB inverted fluorescent microscope (Leica, Solms, Germany). At least three non-overlapped fields were acquired from each well under different treatment conditions, the number of stained cells was counted using ImageJ software and the percentage of PI-positive cells/total (both Calcein and PI positive cells) was calculated. The cell apoptosis index was measured using the DeadEnd Fluorometric TUNEL System (Promega) following the manufacturer's instructions.

Caspase activity assay. Cells treated with HAMLET, OA or HLA alone for $3 \mathrm{~h}$ were harvested and incubated in culture media with $10 \mu \mathrm{mol} / \mathrm{I}$ of FAM-LETDFMK (caspase-8 fluorescent substrate) or FAM-LEHD-FMK (caspase-9 fluorescent substrate) for $1 \mathrm{~h}$ at $37^{\circ} \mathrm{C}$. After washing thrice with Apoptosis Wash Buffer, the cells were suspended in $300 \mu \mathrm{l}$ buffers and analyzed with a fluorescence microscope in three independent experiments.

Electron microscopy. Cells were fixed with $3 \%$ glutaraldehyde in $0.1 \mathrm{~mol} / \mathrm{l}$ phosphate buffer $\left(\mathrm{pH} 7.4\right.$ ), followed by the fixation with $1 \% \mathrm{OsO}_{4}$. After dehydration, 10-nm thin sections were prepared and stained with uranyl acetate and plumbous nitrate before examined under a JEM-1230 transmission electron microscope (JEOL, Tokyo, Japan). High-resolution digital images were acquired from a randomly selected 10 different fields for samples of each condition.
Confocal fluorescence microscopy. Cells were growed on an 12-well slide and co-transfected with GFP-LC3 and RFP-p62 plasmid by using Fugene HD reagents for $48 \mathrm{~h}$. These cells were treated with HAMLET for $3 \mathrm{~h}$, and then were fixed for $15 \mathrm{~min}$ with $4 \%$ paraformaldehyde in PBS. Confocal microscopy studies were performed with an Leica TCS SP5 MP system.

RNA interference. RNA interference against Atg5 was performed by pSUPER-siAtg 5 vector transfection. Cells were grown in six-well plates and transfected with pSUPER-siAtg5 or pSUPER-basic using Fugene HD reagents. At $60 \mathrm{~h}$ post transfection the knockdown protein levels were examined by western blot. The targeted fragment of siRNAs against p62 was $5^{\prime}$-GCATTGAAGTTGATATCGAT-3, as previously published. ${ }^{51}$ Cells were grown in six-well plates and transfected using Fugene HD reagents with siRNA or the scrambled control (Augct, Beijing, China) at a final concentration $20 \mathrm{nmol} / /$. After $72 \mathrm{~h}$, the p62 protein levels were examined by western blot and cells in parallel conditions were used for HAMLET experiments.

Western blots. Cells in 6six-well plates were lysed in $80-100 \mathrm{ul}$ modified RIPA buffer (Thermo, Rockford, IL,USA) containing the full cocktail of protease inhibitors (Thermo). Protein concentrations were determined with the BCA protein assay kit (Novagen, San Diego, CA, USA).Then, proteins were separated by 10 or $15 \%$ SDS-PAGE and transferred to nitrocellulose filters, and blotted with accorded antibodies; secondary antibodies pre-labeled with IRDye800CW or IRDye700CW were used for scanning by Odyssey (LI-COR Biosciences, Lincoln, NE, USA).

Statistical analysis. The experimental data presented in this study were from at least three independent experiments. The data values in the protein degradation assays, calcein-AM/PI staining analysis, GFP-LC3 puncta counting, and cell viability are presented as means with S.E., following one-way ANOVA and Student's $t$ - tests; $P$-value $<0.05$ was considered statistically significant.

\section{Conflict of Interest}

The authors declare no conflict of interest.

Acknowledgements. This study was supported by Chinese Natural Science foundation Grants (30970161 and 30771062). We thank Dr. Terje Johansen for providing the GFP-p62 plasmid and professor Ying-Yu Chen for the GFP-LC3 plasmid. We also thank Dr. Chen-Guang Zhang at Department of Medical Genetics of CCMU for his contribution for the revision of this paper.

1. Svensson M, Duringer C, Hallgren $O$, Mossberg AK, Hakansson A, Linse $S$ et al. Hamlet-a complex from human milk that induces apoptosis in tumor cells but spares healthy cells. Adv Exp Med Biol 2002; 503: 125-132.

2. Gustafsson L, Hallgren O, Mossberg AK, Pettersson J, Fischer W, Aronsson A et al. HAMLET kills tumor cells by apoptosis: structure, cellular mechanisms, and therapy. J Nutr. 2005; 135: 1299-1303.

3. Fischer W, Gustafsson L, Mossberg AK, Gronli J, Mork S, Bjerkvig R et al. Human alphalactalbumin made lethal to tumor cells (HAMLET) kills human glioblastoma cells in brain xenografts by an apoptosis-like mechanism and prolongs survival. Cancer Res 2004; 64: 2105-2112.

4. Mossberg AK, Wullt B, Gustafsson L, Mansson W, Ljunggren E, Svanborg C. Bladder cancers respond to intravesical instillation of HAMLET (human alpha-lactalbumin made lethal to tumor cells). Int J Cancer 2007; 121: 1352-1359.

5. Kohler C, Gogvadze V, Hakansson A, Svanborg C, Orrenius S, Zhivotovsky B. A folding variant of human alpha-lactalbumin induces mitochondrial permeability transition in isolated mitochondria. Eur J Biochem 2001; 268: 186-191.

6. Duringer C, Hamiche A, Gustafsson L, Kimura H, Svanborg C. HAMLET interacts with histones and chromatin in tumor cell nuclei. J Biol Chem 2003; 278: 42131-42135.

7. Gustafsson L, Aits S, Onnerfjord P, Trulsson M, Storm P, Svanborg C. Changes in proteasome structure and function caused by HAMLET in tumor cells. PLoS One 2009; 4: e5229.

8. Hallgren O, Gustafsson L, Irjala H, Selivanova G, Orrenius S, Svanborg C. HAMLET triggers apoptosis but tumor cell death is independent of caspases, Bcl-2 and p53. Apoptosis 2006; 11: 221-233.

9. Aits S, Gustafsson L, Hallgren O, Brest P, Gustafsson M, Trulsson M et al. HAMLET (human alpha-lactalbumin made lethal to tumor cells) triggers autophagic tumor cell death. Int J Cancer 2009; 124: 1008-1019.

10. Brech A, Ahlquist T, Lothe RA, Stenmark H. Autophagy in tumour suppression and promotion. Mol Oncol 2009; 3: 366-375. 
11. Moscat J, Diaz-Meco MT. p62 at the crossroads of autophagy, apoptosis, and cancer. Cell 2009; 137: 1001-1004.

12. Lee JY, Nagano Y, Taylor JP, Lim KL, Yao TP. Disease-causing mutations in parkin impair mitochondrial ubiquitination, aggregation, and HDAC6-dependent mitophagy. J Cell Biol 2010; 189: 671-679.

13. Matsumoto G, Wada K, Okuno M, Kurosawa M, Nukina N. Serine 403 phosphorylation of p62/SQSTM1 regulates selective autophagic clearance of ubiquitinated proteins. Mol Cell 2011; 44: 279-289.

14. Seo G, Kim SK, Byun YJ, Oh E, Jeong SW, Chae GT et al. Hydrogen peroxide induces Beclin 1-independent autophagic cell death by suppressing the mTOR pathway via promoting the ubiquitination and degradation of Rheb in GSH-depleted RAW 264.7 cells. Free Radic Res 2011; 45: 389-399.

15. Nagaoka U, Kim K, Jana NR, Doi H, Maruyama M, Mitsui K et al. Increased expression of p62 in expanded polyglutamine-expressing cells and its association with polyglutamine inclusions. J Neurochem 2004; 91: 57-68.

16. Sohn D, Schulze-Osthoff K, Janicke RU. Caspase-8 can be activated by interchain proteolysis without receptor-triggered dimerization during drug-induced apoptosis. J Biol Chem 2005; 280: 5267-5273.

17. Kamijima T, Ohmura A, Sato T, Akimoto K, Itabashi M, Mizuguchi M et al. Heat-treatment method for producing fatty acid-bound alpha-lactalbumin that induces tumor cell death. Biochem Biophys Res Commun 2008; 376: 211-214.

18. Zhang YB, Zeng RX, Niu J, Zheng SP, Jia HT, Ding W. Fast and scalable production of cancer-killing complex from recombinant human alpha-lactalbumin and oleic acid. J Capital Med Univ 2012; 33: 557-564.

19. Svensson M, Mossberg AK, Pettersson J, Linse S, Svanborg C. Lipids as cofactors in protein folding: stereo-specific lipid-protein interactions are required to form HAMLET (human alpha-lactalbumin made lethal to tumor cells). Protein Sci 2003; 12 : 2805-2814.

20. Mercer N, Ramakrishnan B, Boeggeman E, Qasba PK. Applications of site-specific labeling to study HAMLET, a tumoricidal complex of alpha-lactalbumin and oleic acid. PLoS One 2011; 6: e26093.

21. Svensson M, Hakansson A, Mossberg AK, Linse S, Svanborg C. Conversion of alpha-lactalbumin to a protein inducing apoptosis. Proc Natl Acad Sci USA 2000; 97 : 4221-4226

22. Mok KH, Pettersson J, Orrenius S, Svanborg C. HAMLET, protein folding, and tumor cell death. Biochem Biophys Res Commun. 2007; 354: 1-7.

23. Hallgren O, Aits S, Brest P, Gustafsson L, Mossberg AK, Wullt B et al. Apoptosis and tumor cell death in response to HAMLET (human alpha-lactalbumin made lethal to tumor cells) Adv Exp Med Biol 2008; 606: 217-240.

24. Hu YL, DeLay M, Jahangiri A, Molinaro AM, Rose SD, Carbonell WS et al. Hypoxiainduced autophagy promotes tumor cell survival and adaptation to antiangiogenic treatment in glioblastoma. Cancer Res 2012; 72: 1773-1783.

25. Young JE, Martinez RA, La Spada AR. Nutrient deprivation induces neuronal autophagy and implicates reduced insulin signaling in neuroprotective autophagy activation. $J$ Biol Chem 2009; 284: 2363-2373.

26. Pankiv S, Clausen TH, Lamark T, Brech A, Bruun JA, Outzen H et al. p62/SQSTM1 binds directly to Atg8/LC3 to facilitate degradation of ubiquitinated protein aggregates by autophagy. J Biol Chem 2007; 282: 24131-24145.

27. Gal J, Strom AL, Kilty R, Zhang F, Zhu H. p62 accumulates and enhances aggregate formation in model systems of familial amyotrophic lateral sclerosis. J Biol Chem 2007; 282: 11068-11077.

28. Young M, Takahashi Y, Khan O, Park S, Hori T, Yun J et al. Autophagosomal membrane serves as a platform for an intracellular death-inducing signaling complex (iDISC)-mediated caspase-8 activation and apoptosis. J Biol Chem 2012; 287: 12455-12468.

29. Laussmann MA, Passante E, Dussmann H, Rauen JA, Wurstle ML, Delgado ME et al. Proteasome inhibition can induce an autophagy-dependent apical activation of caspase-8. Cell Death Differ 2011; 18: 1584-1597.

30. Baltzer A, Svanborg C, Jaggi R. Apoptotic cell death in the lactating mammary gland is enhanced by a folding variant of alpha-lactalbumin. Cell Mol Life Sci 2004; 61: 1221-1228.
31. Casbarra A, Birolo L, Infusini G, Dal Piaz F, Svensson M, Pucci P et al. Conformational analysis of HAMLET, the folding variant of human alpha-lactalbumin associated with apoptosis. Protein Sci 2004; 13: 1322-1330.

32. Salazar M, Carracedo A, Salanueva IJ, Hernandez-Tiedra S, Lorente M, Egia A et al. Cannabinoid action induces autophagy-mediated cell death through stimulation of ER stress in human glioma cells. J Clin Invest 2009; 119: 1359-1372.

33. Zhang YB, Wu W, Ding W. From HAMLET to XAMLET: the molecular complex selectively induces cancer cell death. Afri J Biotech 2010; 9: 9270-9276.

34. Hara T, Nakamura K, Matsui M, Yamamoto A, Nakahara Y, Suzuki-Migishima R et al. Suppression of basal autophagy in neural cells causes neurodegenerative disease in mice. Nature 2006; 441: 885-889.

35. Mizushima N, Levine B, Cuervo AM, Klionsky DJ. Autophagy fights disease through cellular self-digestion. Nature 2008; 451: 1069-1075.

36. Moore MN. Autophagy as a second level protective process in conferring resistance to environmentally-induced oxidative stress. Autophagy 2008; 4: 254-256.

37. Isaka Y, Kimura T, Takabatake Y. The protective role of autophagy against aging and acute ischemic injury in kidney proximal tubular cells. Autophagy 2011; 7: 1085-1087.

38. Debnath J, Baehrecke EH, Kroemer G. Does autophagy contribute to cell death? Autophagy 2005; 1: 66-74.

39. Kroemer G, Levine B. Autophagic cell death: the story of a misnomer. Nat Rev Mol Cell Biol 2008; 9: 1004-1010.

40. Ichimura Y, Komatsu M. Selective degradation of $p 62$ by autophagy. Semin Immunopathol 2010; 32: 431-436.

41. Mathew R, Karp CM, Beaudoin B, Vuong N, Chen G, Chen HY et al. Autophagy suppresses tumorigenesis through elimination of p62. Cell 2009; 137: 1062-1075.

42. Kwon J, Han E, Bui CB, Shin W, Lee J, Lee S et al. Assurance of mitochondrial integrity and mammalian longevity by the p62-Keap1-Nrf2-Nqo1 cascade. EMBO Rep 2012; 13: 150-156.

43. Thompson HG, Harris JW, Wold BJ, Lin F, Brody JP. p62 overexpression in breast tumors and regulation by prostate-derived Ets factor in breast cancer cells. Oncogene 2003; 22: 2322-2333.

44. Hou W, Han J, Lu C, Goldstein LA, Rabinowich H. Autophagic degradation of active caspase-8: a crosstalk mechanism between autophagy and apoptosis. Autophagy 2010; 6: 891-900.

45. Pan JA, Fan Y, Gandhirajan RK, Madesh M, Zong WX. Hyperactivation of the mammalian degenerin MDEG promotes caspase-8 activation and apoptosis. J Biol Chem 2013; 288: 2952-2963.

46. Permyakov SE, Knyazeva EL, Khasanova LM, Fadeev RS, Zhadan AP, Roche-Hakansson H et al. Oleic acid is a key cytotoxic component of HAMLET-like complexes. Biol Chem 2012; 393: 85-92.

47. Kovacs JR, Li C, Yang Q, Li G, Garcia IG, Ju S et al. Autophagy promotes T-cell survival through degradation of proteins of the cell death machinery. Cell Death Differ 2012; 19: 144-152.

48. Yang W, Monroe J, Zhang Y, George D, Bremer E, Li H. Proteasome inhibition induces both pro- and anti-cell death pathways in prostate cancer cells. Cancer Lett 2006; 243: 217-227.

49. Calamai M, Chiti F, Dobson CM. Amyloid fibril formation can proceed from different conformations of a partially unfolded protein. Biophys J 2005; 89: 4201-4210.

50. Tanaka T, Kai S, Koyama T, Daijo H, Adachi T, Fukuda K et al. General anesthetics inhibit erythropoietin induction under hypoxic conditions in the mouse brain. PLoS One 2011; 6: e29378.

51. Pankiv S, Lamark T, Bruun JA, Overvatn A, Bjorkoy G, Johansen T. Nucleocytoplasmic shuttling of p62/SQSTM1 and its role in recruitment of nuclear polyubiquitinated proteins to promyelocytic leukemia bodies. J Biol Chem 2010; 285: 5941-5953.

(c) (1) (-) Cell Death and Disease is an open-access journal published by Nature Publishing Group. This work is licensed under a Creative Commons Attribution-NonCommercialShareAlike 3.0 Unported License. To view a copy of this license, visit http://creativecommons.org/licenses/by-nc-sa/3.0/ 